\title{
Association between IL23R and ERAPI polymorphisms and sacroiliac or spinal MRI inflammation in spondyloarthritis: DESIR cohort data
}

Adeline Ruyssen-Witrand ${ }^{1 *}$, Cécile Luxembourger ${ }^{1}$, Alain Cantagrel ${ }^{2}$, Delphine Nigon ${ }^{3}$, Pascal Claudepierre ${ }^{4}$, Yannick Degboe ${ }^{2}$ and Arnaud Constantin ${ }^{2}$

\begin{abstract}
Background: To investigate the association between 12 single nucleotide polymorphisms (SNPs) located on ERAP1 and IL23R with the presence of inflammation on the sacroiliac joint (SIJ) or spinal magnetic resonance imagery (MRI) in an early onset spondyloarthritis (SpA) cohort.

Methods: All the patients included in the DESIR cohort with an axial SpA and available DNA at baseline were enrolled in this study ( $n=645$ patients) and underwent a clinical examination, CRP assay, SIJ and spinal MRI scans. Six SNPs located on ERAP1 (rs30187, rs27044, rs27434, rs17482078, rs 10050860, rs2287987) and six SNPs located on IL23R (rs 1004819, rs 10489629, rs 1343151, rs2201841, rs 10889677, rs11209032) were genotyped. Univariable analyses were performed to test the association between the genotypes and SIJ and spinal MRI inflammation, as well as disease activity based on Bath Ankylosing Spondylitis Disease Activity Index (BASDAI), Ankylosing Spondylitis Disease Activity Score-C-Reactive Protein (ASDAS-CRP) and CRP.

Results: One SNP located on ERAP1 (rs27434) and haplotype CCT of ERAP1 were associated with SIJ inflammation detected by MRI, but these associations were below the Bonferroni corrected threshold of significance. However, one SNP (rs1004819) located on IL23R was associated with SIJ MRI inflammation (rs1004819: TT 42.3\%, CT 40.5\%, CC $26.5 \%, p=0.0005$ ). This locus was also significantly associated with Spondyloarthritis Research Consortium of Canada scores while no association with another inflammatory parameter such as BASDAI, ASDAS-CRP, CRP or Berlin MRI score was identified in this population.
\end{abstract}

Conclusion: One locus of the IL23R gene was associated with SIJ MRI inflammation and might be a marker of more active disease in recent onset SpA.

Trial registration: clinicaltrials.gov, NCTO 1648907

Keywords: Spondyloarthritis, Sacroiliitis, Polymorphisms

\footnotetext{
* Correspondence: ruyssen-witrand.a@chu-toulouse.fr

${ }^{1}$ Centre de rhumatologie, CHU de Toulouse, UMR 1027, Inserm, Université

Paul Sabatier Toulouse III, Toulouse, France

Full list of author information is available at the end of the article
}

(c) The Author(s). 2019 Open Access This article is distributed under the terms of the Creative Commons Attribution 4.0 International License (http://creativecommons.org/licenses/by/4.0/), which permits unrestricted use, distribution, and reproduction in any medium, provided you give appropriate credit to the original author(s) and the source, provide a link to the Creative Commons license, and indicate if changes were made. The Creative Commons Public Domain Dedication waiver (http://creativecommons.org/publicdomain/zero/1.0/) applies to the data made available in this article, unless otherwise stated. 


\section{Background}

Spondyloarthritis (SpA) is a common, highly heritable form of inflammatory arthritis that primarily affects the spine and pelvis. The first genetic determinant of this disease is the presence of $H L A-B 27$ susceptibility alleles for which 114 subtypes are now recognised [1].

The presence of $H L A-B 27$ is the major genetic factor implicated in disease susceptibility. Nevertheless, other genes are also involved in the genetic background for SpA since $H L A-B 27$ is detected in around $90 \%$ of patients with ankylosing spondylitis (AS) and in $30-50 \%$ of cases involving other SpA subtypes such as psoriatic arthritis (PsA) or SpA associated with inflammatory bowel disease [2].

Several genome-wide association (GWA) studies have been published on AS susceptibility in individuals from European and Asian populations, which have identified at least 31 significant non-HLA genetic loci. These genes account for up to $25 \%$ of the overall heritability of AS, with the overwhelming majority provided by $H L A-B 27$ per se $[2,3]$. Among these recently identified loci, variations within genes encoding proteins involved in interferon or tumour necrosis factor/NFkB signalling and transcription have been identified, as well as genes influencing IL-23/IL-17 signalling or TCD8+ differentiation or genes encoding proteins crucial for antigen presentation [3].

Among these novel loci, ERAP1 variants have been widely replicated by GWA studies in populations of white European ancestry and in Eastern Asians $[4,5]$. ERAP1 variants alter the quantity, length and stability of peptides presented to the peptide-MHC molecule [6]. Furthermore, several variants located on IL23R have also been shown to be associated with SpA susceptibility in several studies $[3,7,8]$.

Although these associations have often been replicated in several different populations, the association of these polymorphisms with the disease phenotype and especially disease activity assessed by magnetic resonance imaging (MRI) inflammation has been poorly investigated.

The aim of this study was to investigate the association between 12 SNPs located on ERAP1 and IL23R genes and sacroiliac joint (SIJ) or spinal MRI inflammation in a cohort of newly diagnosed SpA patients (DESIR cohort).

\section{Patients and methods}

\section{Study population}

The DEvenir des Spondyloarthrites Indifférenciées Récentes (DESIR) cohort has already been described in the literature [9]. In short, DESIR is a French, long-term prospective longitudinal cohort study monitoring 708 patients (between 18 and 50 years of age) presenting inflammatory back pain (IBP) suggestive of axial SpA for $\geq 3$ months and $<3$ years, according to their rheumatologist, included in 25 centres across France between 2007 and 2010. All patients included in the study underwent a baseline collection of clinical data, blood samples, unenhanced pelvic and spinal X-rays, SIJ and spinal MRI. Among these patients, 645 with DNA specimens and fulfilling at least 1 spondyloarthritis classification criteria including axial Assessment of Spondyloarthritis international Society (ASAS) criteria 2009 [10], Amor criteria [11], ESSG criteria [12] or modified New York criteria [13] were selected for the present study. The baseline database of the DESIR cohort was used for this study (dataset locked on June 30, 2010).

\section{Ethics, consent and permission}

The study complied with Good Clinical Practice Guidelines (clinicaltrials.gov: NCTO 164 8907, https://clinical trials.gov/ct2/show/NCT01648907) and was approved by the appropriate Medical Ethics Committee (CPP Ilede-France III, submission number P070302). Patients gave their informed consent before the study started, including their permission for any anonymously processed data to be published.

\section{Genetic polymorphisms}

Genotyping of the IL23R (rs1004819, rs10489629, rs13 43151, rs2201841, rs10889677, rs11209032) and ERAP1 (rs30187, rs27044, rs27434, rs17482078, rs10050860, rs22 87987) polymorphisms was performed by LGC Genomics Platform (UK) using allele-specific kinetic polymerase chain reaction analysis and the KASPar method (accuracy generally $>99 \%$, error rate $<0.3 \%$ ). These 12 SNPs were selected because they were associated with SpA susceptibility [3-8] or located close to a SNP associated with SpA susceptibility with an allele frequency $>0.1$ in the Caucasian population.

\section{Imaging data}

An MRI scan of the SIJ and spine was performed at the outset in each participating centre using 1.0-1.5 $\mathrm{T}$ machines.

\section{MRI sacroiliitis definition as primary outcome}

The acquired sequences were coronal oblique T1-weighted FSE and STIR images with 12-15 semi-coronal slices, each 4-mm-thick, parallel to the long axis of the sacrum. All available baseline SIJ MRIs were read centrally and independently by 2 readers, blinded for all clinical and laboratory data. SIJ MRI scans were considered positive according to the ASAS definition [14] if bone marrow oedema lesions, highly indicative of $\mathrm{SpA}$, were present (i.e. if $\geq 1$ bone marrow oedema lesions were visible on $\geq 2$ consecutive slices, or if several bone marrow oedema lesions were visible on a single slice). Inter-reader agreement for the definition of MRI-detected sacroiliitis was good (kappa score of approximately 0.74$)$ [15]. When central readers disagreed on the presence of inflammation on the spine or SI MRI, a senior radiologist involved the MRI and served as adjudicator blinded to the information of the primary readers. 


\section{Other secondary imaging outcomes}

The two readers also scored the MRI scans (intra-class correlation coefficient of around 0.94 for absolute baseline scores) for the presence of inflammatory lesions according to the Spondyloarthritis Research Consortium of Canada (SPARCC) scoring method (range 0-72) [16].

MRI scans of the thoracic spine and lumbar spine were performed using the T1-weighted spin-echo and short-tau inversion recovery sequences. Inflammatory lesions were centrally scored by two independent readers, blinded to the clinical data. A positive spinal MRI was defined according to the ASAS consensus (i.e. $\geq 3$ inflammatory lesions) [17] and using the Berlin method [18]. Agreement between readers for an ASAS-defined positive spinal MRI was moderate $(k=0.58)$ [19].

All MRI scans were centrally scored by two trained readers and expressed in positive MRI sacroiliitis according to the ASAS definition or not, size of bone marrow oedema according to the Spondyloarthritis Research Consortium of Canada (SPARCC) scoring method (range 0-72) and positive spinal MRI according to the ASAS consensus definition and MRI spine inflammation using the Berlin method.

Sacroiliitis on X-rays was centrally assessed according to the modified New York criteria [13] by two different, blinded, trained readers (moderate inter-reader agreement with a kappa score of around 0.54) [20].

\section{Other clinical and biological data}

For the present study, demographic characteristics including age, sex, disease duration and disease activity data were analysed at the outset. The markers of disease activity included the Bath Ankylosing Spondylitis Disease Activity Index (BASDAI) and the Ankylosing Spondylitis Disease Activity Score-C-Reactive Protein (ASDAS-CRP) and were studied as potential cofounders for the primary analysis.

C-reactive protein (CRP) and HLA-B27 status were measured at baseline and studied as potential cofounders for the primary analysis.

\section{Statistical analysis}

Tests for deviation from the Hardy-Weinberg equilibrium (HWE) were performed using a standard $\chi^{2}$ test (1 d.f.). A linkage disequilibrium was investigated within SNPs located on the same gene using PLINK v1.07 software, and in the case of a strong linkage disequilibrium (defined by a $r^{2}>0.8$ and $D^{\prime}=1$ ), a haplotype of the SNPs in linkage disequilibrium was created for analytic purposes with Haploview software.

The primary outcome was to investigate the association between the SNPs and haplotypes of SNPs and SIJ MRI inflammation using a Fisher test or chi-square test and the Cochrane-Armitage test for trends. A Bonferroni correction was applied to the result of the CochraneArmitage trend test for this analysis taking multiple tests into account. In case of association, epistatic interactions between the locus and $H L A-B 27$ were investigated using two different methods: the RERI method and PLINK epistasis software v1.07 [21]. In the event of an interaction, the results were stratified on HLA-B27 carriage.

If a significant association was detected, other associations between the SNPs and/or haplotypes and activity assessed by BASDAI, ASDAS-CRP, CRP, MRI oedema size assessed by using the SPARCC score or structural damage radiographic sacroiliitis (New York criteria) were further assessed, using a Fisher test or chi-square test and the Cochrane-Armitage test for trends in the case of qualitative variables or Kruskal-Wallis and Cuzick trend tests for quantitative variables. Considering all the multiple tests performed, the threshold of significance after Bonferroni correction was set at approximately 0.0033 . Assuming that a meaningful difference of $15 \%$ in the prevalence of MRI sacroiliitis between allele carriers and non-carriers, and knowing that $34 \%$ of the DESIR patients had a MRI sacroiliitis, and that minor allele prevalence of the different SNPs was about 0.3 in most cases, the power to identify an association with an alpha risk of 0.0033 was estimated between 74 and $80 \%$.

Finally, to investigate whether the association between the SNPs were independently associated with MRI sacroiliitis, a multivariable analysis using logistic regression, backward procedure, was performed including other potential cofounding variables such as age, gender, $H L A-B 27$ presence, CRP, ASDAS-CRP and NSAIDs intake.

\section{Results}

All of the 12 SNPs fit the Hardy-Weinberg equilibrium expectations $(p>0.05)$ and had an allele frequency $>0.10$ in the DESIR cohort. The genotyping success rate was approximately $98.8 \%$, and 645 patients could be enrolled in this study whose characteristics are summarised in Table 1.

Three SNPs located on the ERAP1 gene (rs17482078, rs10050860, rs2287987) demonstrated strong linkage disequilibrium $\left(r^{2}\right.$ ranging between 0.97 and $\left.0.99, D^{\prime}=1\right)$, and a haplotype of these three loci was thus created and used for further analyses. Two SNPs located on the IL23R gene (rs2201841 and rs10889677) also showed strong linkage disequilibrium $\left(r^{2}=0.96, D^{\prime}=1\right)$, and a haplotype including these two loci was created and used for further analyses.

\section{Association between ERAP1, IL23R and SIJ MRI inflammation}

None of the three SNPs and the haplotype located on ERAP1 was associated with SIJ MRI inflammation when applying Bonferroni correction. 
Table 1 Baseline characteristics of the patients enrolled

\begin{tabular}{ll}
\hline & Study population, $n=645$ \\
\hline Age, med (IQR) & $32.9(26.5-39.7)$ \\
Gender, number of males (\%) & $299(46.4)$ \\
Disease duration, months, med (IQR) & $17.1(9.6-26.5)$ \\
Positive HLA-B27, number (\%) & $403(62.6)$ \\
BASDAl, med (IQR) & $46(29-61)$ \\
ASDAS-CRP, med (IQR) & $2.7(2.0-3.4)$ \\
CRP (mg/L), med (IQR) & $3.2(2-8)$ \\
NSAIDs intake, $n$ (\%) & $451(71.5)$ \\
Radiographic sacroiliitis, $n$ (\%) & $184(28.9)$ \\
mSASSS, med (IQR) & $0(0-0)$ \\
Presence of MRI sacroiliitis, $n$ (\%) & $214(34.2)$ \\
MRI SPARCC, med (IQR) & $0(0-4)$ \\
ASAS positive spinal MRI, $n$ (\%) & $49 / 603(8.1)$ \\
Spinal MRI Berlin score, med (IQR) & $0(0-0)$
\end{tabular}

BASDAI Bath Ankylosing Spondylitis Disease Activity Index, ASDAS-CRP Ankylosing Spondylitis Disease Activity Score with CRP, mSASSS Modified Stoke Ankylosing Spondylitis Spine Score, SPARCC Spondyloarthritis Research Consortium of Canada scoring system (sacro-iliac joints MRI scoring system), Berlin score spinal MRI scoring system

After applying a Bonferroni correction, only the rs1004819, located on $I L 23 R$, remained significantly associated with the presence of SIJ MRI inflammation and was thus further investigated (Table 2). This locus was thus also associated with sacroiliac oedema size assessed by SPARCC score ( $p$ for the association, 0.001; Table 3, Fig. 1). However, this locus was neither associated with other inflammatory parameters (ASDAS CRP, BASDAI, CRP of MRI spinal inflammation assessed by Berlin score) nor radiographic sacroiliitis (Table 3).

\section{Epistatic interaction between rs1004819 on IL23R and HLA-B27 allele carriage}

Epistatic interactions between the SNP of IL23R and $H L A-B 27$ were investigated to assess whether $H L A-B 27$ allele carriage could interact with the association between rs1004819 and MRI sacroiliitis using two different methods: the RERI method and PLINK epistasis software v1.07 [21]. No epistatic interaction was identified between rs1004819 and HLA-B27 allele carriage for the association with MRI sacroiliitis.

Mutivariable analysis assessing the risk of MRI sacroiliitis according to rs1004819 genotype

After logistic regression including other cofounding variables such as gender, age, HLA-B27 presence, CRP, ASDAS-CRP and NSAIDs intake, rs1004819 genotype remained independently associated with MRI sacroiliitis (Table 4).
Table 2 Association between MRI sacroiliac inflammation and IL23R and ERAP1 SNP and haplotype genotypes

\begin{tabular}{|c|c|c|c|}
\hline & $\begin{array}{l}\text { Number of } \\
\text { patients (\%) }\end{array}$ & $\begin{array}{l}p \text { value comparison } \\
\text { of distribution }\end{array}$ & $\begin{array}{l}p \text { value for Cochran- } \\
\text { Armitage trend test }\end{array}$ \\
\hline \multicolumn{4}{|l|}{ ERAP1 } \\
\hline \multicolumn{4}{|l|}{ rs27044 } \\
\hline GG & $21(39.62)$ & 0.5 & 0.25 \\
\hline$C G$ & $98(35.25)$ & & \\
\hline $\mathrm{CC}$ & 94 (32.19) & & \\
\hline \multicolumn{4}{|l|}{ rs30187 } \\
\hline$\pi$ & $36(37.5)$ & 0.07 & 0.04 \\
\hline $\mathrm{CT}$ & $113(37.5)$ & & \\
\hline $\mathrm{CC}$ & 65 (28.4) & & \\
\hline \multicolumn{4}{|l|}{ rs27434 } \\
\hline GG & $105(30.3)$ & 0.04 & 0.01 \\
\hline$A G$ & $92(38.1)$ & & \\
\hline $\mathrm{AA}$ & $16(47.1)$ & & \\
\hline \multicolumn{4}{|c|}{ Haplotype CCT* } \\
\hline 0 copy & $4(14.8)$ & 0.02 & 0.007 \\
\hline 1 copy & $55(29.4)$ & & \\
\hline 2 copies & 153 (37.2) & & \\
\hline \multicolumn{4}{|l|}{ IL23R } \\
\hline \multicolumn{4}{|l|}{ rs1004819 } \\
\hline$\pi$ & $30(42.3)$ & 0.001 & 0.0005 \\
\hline$C T$ & $109(40.5)$ & & \\
\hline $\mathrm{CC}$ & $75(26.5)$ & & \\
\hline \multicolumn{4}{|l|}{ rs10489629 } \\
\hline GG & $35(29.2)$ & 0.3 & 0.1 \\
\hline$A G$ & $101(33.8)$ & & \\
\hline $\mathrm{AA}$ & 77 (38.1) & & \\
\hline \multicolumn{4}{|l|}{ rs1343151 } \\
\hline$\pi$ & $24(30.4)$ & 0.02 & 0.02 \\
\hline $\mathrm{CT}$ & $82(29.5)$ & & \\
\hline $\mathrm{CC}$ & $108(40.3)$ & & \\
\hline \multicolumn{4}{|l|}{ rs11209032 } \\
\hline GG & $74(35.4)$ & 0.03 & 0.01 \\
\hline$A G$ & $109(47.3)$ & & \\
\hline AA & $26(41.3)$ & & \\
\hline \multicolumn{4}{|c|}{ Haplotype GA* } \\
\hline 0 copy & $80(28.9)$ & 0.02 & 0.0054 \\
\hline 1 copy & $103(37.6)$ & & \\
\hline 2 copies & $30(44.1)$ & & \\
\hline
\end{tabular}

*: Haplotype CCT: rs17482078, rs10050860, rs2287987; haplotype GA: rs2201841, rs 10889677

\section{Discussion}

This work aimed to investigate the association between 12 loci located on ERAP1 and IL23R genes and SIJ or 
Table 3 Association between rs1004819 located on IL23R genotypes and clinical and biological activity, SPARCC score and MRIdetected spinal inflammation

\begin{tabular}{lllll}
\hline rs1004819, by genotype & $T$ & $C T$ & CC & $\begin{array}{l}\text { Comparison* across genotypes } \\
p \text { value }\end{array}$ \\
\hline BASDAl, med (IQR) & $38(24-53)$ & $48(30-62)$ & $48(28-62)$ & 0.1 \\
ASDAS-CRP med (IQR) & $2.5(1.7-3.3)$ & $2.8(2.0-3.4)$ & $2.7(2.0-3.4)$ & 0.5 \\
CRP, med (IQR) & $3.6(2.0-8.0)$ & $3.5(2.0-7.0)$ & $3(2.0-8.8)$ & 0.3 \\
SPARCC, med (IQR) & $0.0(0.0-8.0)$ & $0.5(0.0-5.5)$ & $0.0(0.0-2.0)$ & 0.0008 \\
Patients with MRI spinal inflammation, $n(\%)$ & $11(15.9)$ & $20(7.8)$ & $18(6.6)$ & 0.03 \\
Berlin score, med (IQR) & $0(0-1)$ & $0(0-0)$ & $0(0-0)$ & 0.09
\end{tabular}

${ }^{*} p$ value with a Cochrane-Armitage trend test in case of dichotomous variable and Cuzick trend tests in case of continuous variable BASDAl Bath Ankylosing Spondylitis Disease Activity Index, ASDAS-CRP Ankylosing Spondylitis Disease Activity Score with CRP, mSASSS Modified Stoke Ankylosing Spondylitis Spine Score, SPARCC Spondyloarthritis Research Consortium of Canada scoring system (sacroiliac joints MRI scoring system), Berlin score spinal MRI scoring system

spinal MRI inflammation in a cohort of 625 patients with recent onset axial SpA (DESIR cohort). In this study, rs1004819 located on the IL23R gene was associated with the presence of MRI sacroiliitis and MRI bone oedema size assessed by the SPARCC score. However, this locus was not associated with the clinical and biological activity, MRI spinal inflammation nor with radiographic sacroiliitis. None of the SNPs studied on ERAP1 was significantly associated with SIJ or spinal MRI inflammation in this study.

IL-23 is a pro-inflammatory cytokine formed via the binding of a shared IL-12p40 unit to a p19 protein secreted primarily by dendritic cells, monocytes and macrophages [22]; IL-23 plays a role in the maintenance of immune responses by controlling $\mathrm{T}$ cell memory function and by activating the proliferation and survival of Th17 cells. IL-23 is thus a key cytokine in several inflammatory diseases including SpA [23]. The IL23R gene is located on chromosome 1 (1p31). In recent years, new therapeutic biological agents targeting the IL-17/IL-23 pathway have proved effective in reducing disease activity, and studies have suggested a preventive role in the structural radiographic progression of spondyloarthritis and psoriatic arthritis [24, 25]. ERAP1 molecules encoded in the endoplasmic reticulum lumen play an important role in peptide trimming for presentation at the cell surface. Reduced trimming of peptides and consequently altered antigen presentation on HLA-B27 molecules is probably an important mechanism involved in AS development and protection [26].

Several studies have previously shown an association between rs11209026 and AS susceptibility [3], as well as radiographic sacroiliitis [27]. In our study, this locus was not genotyped because the allele frequency of this

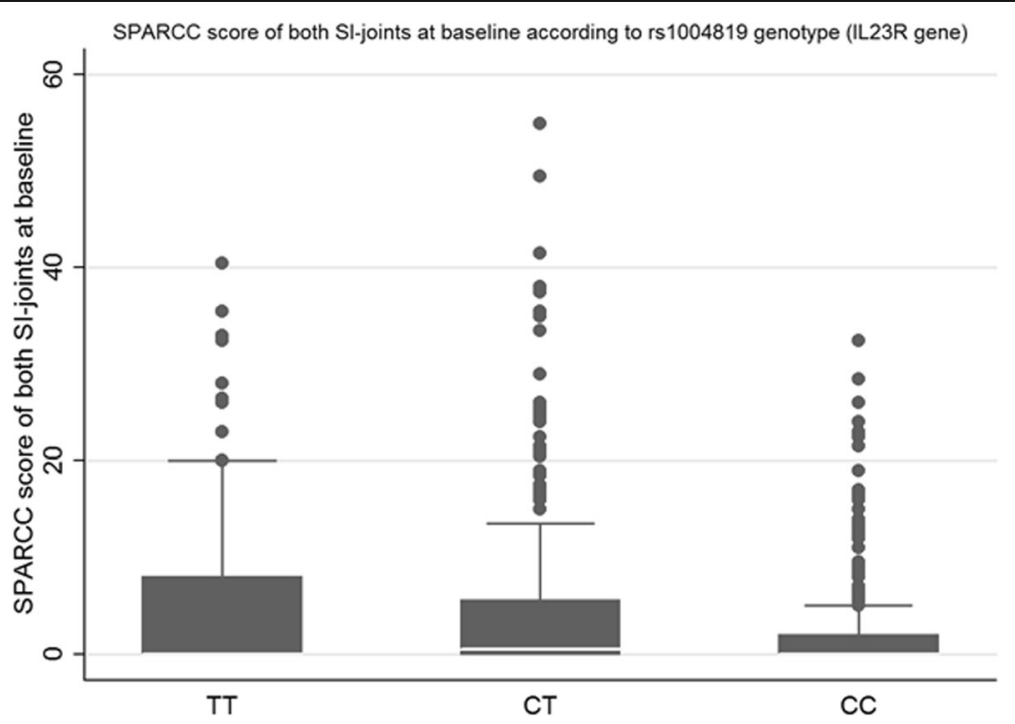

Fig. 1 SPARCC scores of sacroiliac joint MRI according to the genotypes of rs1004819 and GA haplotype of IL23R. SPARCC, Spondyloarthritis Research Consortium of Canada scoring system (sacroiliac joints MRI scoring system) 
Table 4 Logistic regression assessing the risk of MRI sacroiliitis and including rs1004819 genotype, age, gender, HLA-B27 presence and NSAIDs intake

\begin{tabular}{lll}
\hline & OR [95\%Cl] & $p$ value \\
\hline rs1004819 & $0.71[0.53-0.94]$ & 0.02 \\
age & - & NS \\
Gender & $2.15[1.46-3.19]$ & $<0.0001$ \\
CRP (per mg/L) & $1.02[1.00-1.03]$ & 0.01 \\
ASDAS-CRP & - & NS \\
HLA-B27 & $1.95[1.27-2.97]$ & 0.002 \\
NSAIDs intake & - & NS \\
\hline
\end{tabular}

Age ASDAS-CRP and NSAIDs intake were removed after backward procedure OR odds ratio, $\% 95 \mathrm{Cl} 95 \%$ confidence interval, NS non-significant

variant is very low (A allele frequency approximately 0.04 in the general population), and as the study involved a small sample, the power for identifying an association was allegedly too low to be conclusive.

No significant epistatic interaction was identified between rs 1004819 on IL23R and the presence of $H L A-B 27$, thus indicating that the $I L 23 R$ locus is associated with MRI inflammation independently of $H L A-B 27$ allele carriage.

This study has several limitations. Firstly, the work was set on a sample of 625 patients and multiple loci were tested; thus, the power to detect a difference was decreased. However, power calculation in SNPs where minor allele prevalence was about 0.3 revealed a power to detect a difference about $15 \%$ between 74 and $80 \%$. Furthermore, we did not have a second sample to replicate our results, and these findings have to be further confirmed in an independent population. However, this locus is already known to be associated with AS susceptibility and it is established that MRI sacroiliitis can be considered as an early stage of radiographic sacroiliitis and thus predispose to AS disease. In this study, we chose to apply a candidate gene search strategy to identify association between loci already known as susceptibility markers of the disease and MRI inflammation in early SpA patients. Other strategies such as IL23R and ERAP1 DNA sequencing could also be performed to further investigate the association between these genes and MRI inflammation in SpA. Finally, this study investigated only SpA patients with no control group. Thus, these findings identified associations between candidate genes and different phenotypes of $\mathrm{SpA}$, and this study did not demonstrate here that these loci were SpA susceptibility markers.

To the best of our knowledge, this is the first study highlighting the association between genetic polymorphisms outside of the $\mathrm{MHC}$ region known to be associated with AS susceptibility and MRI inflammation in recent onset axial SpA patients. DESIR cohort imaging data was centrally scored by experienced readers blinded to the clinical data, which improves imaging data confidence. The rs1004819, located on IL23R, that is associated with MRI sacroiliitis, has proved to be strongly associated with disease susceptibility. It has also proved to be an apparent marker of inflammatory disease in patients diagnosed with recent onset axial SpA, since it was also associated with MRI sacroiliitis oedema size, assessed via the SPARCC scoring system, and with the presence of an MRI spinal inflammatory lesion.

\section{Conclusion}

In summary, this study identified an association between one locus on the IL23R gene and MRI inflammation located on the spine and SIJ. However, these findings should be replicated in other populations and the role played by these polymorphisms in IL23R gene expression should be further explored.

\section{Abbreviations}

AS: Ankylosing spondylitis; ASAS: Assessment of Spondyloarthritis international Society; ASDAS: Ankylosing Spondylitis Disease Activity Score; axSpA: Axial spondyloarthritis; BASDAl: Bath Ankylosing Spondylitis Disease Activity Index; BASFI: Bath Ankylosing Spondylitis Functional Index; bDMARD: Biologic disease-modifying antirheumatic drugs; CRP: C-reactive protein; DESIR: DEvenir des Spondyloarthites Indifférenciées Récentes; ESSG: European Spondyloarthropathy Study Group; GWA: Genome-wide association; HLA: Human leucocyte antigen; HWE: Hardy-Weinberg equilibrium; IBD: Inflammatory bowel disease; MHC: Major histocompatibility complex; MRI: Magnetic resonance imaging; NSAID: Non-steroidal antiinflammatory drug; PSA: Psoriatic arthritis; SD: Standard deviation; SIJ: Sacroiliac joints; SNP: Single nucleotide polymorphism; SpA: Spondyloarthritis;

SPARCC: Spondyloarthritis Research Consortium of Canada; TNF: Tumour necrosis factor; VAS: Visual analogue scale

\section{Acknowledgements}

The DESIR study is conducted with Assistance Publique Hopitaux de Paris as the sponsor. The DESIR study is also under the umbrella of the French Society of Rheumatology, which financially supports the cohort. An unrestricted grant from Pfizer has been allocated for the first 10 years. The DESIR cohort is

conducted under the control of Assistance publique Hopitaux de Paris via the Clinical Research Unit Paris Centre and under the umbrella of the French Society of Rheumatology and Institut national de la sante et de la recherche medicale (Inserm). Database management is performed within the Department of Epidemiology and Biostatistics (Professeur Jean-Pierre Daures, D.I.M., Nımes, France). We also wish to thank the different regional participating centres: $\mathrm{Pr}$ Maxime Dougados (Paris-Cochin B), Pr Andre Kahan (Paris-Cochin A), Pr Philippe Dieudé (Paris-Bichat), Pr Bruno Fautrel (Paris-La Pitie-Salpetriere), Pr Francis Berenbaum (Paris-Saint-Antoine), Pr Pascal Claudepierre (Creteil), Pr Maxime Breban (Boulogne-Billancourt), Dr Bernadette Saint-Marcoux (Aulnay-sous-Bois), Pr Philippe Goupille (Tours), Pr Jean Francis Maillefert (Dijon), Dr Emmanuelle Dernis (Le Mans), Pr Daniel Wendling (Besancon), Pr Bernard Combe (Montpellier), Pr Liana Euller-Ziegler (Nice), Pr Pascal Richette (ParisLariboisiere), Pr Pierre Lafforgue (Marseille), Dr Patrick Boumier (Amiens), Pr Martin Soubrier (ClermontFerrand), Dr Nadia Mehsen (Bordeaux), Pr Damien Loeuille (Nancy), Pr Rene-Marc Flipo (Lille), Pr Alain Saraux (Brest), Pr Xavier Mariette (LeKremlin-Bicetre), Pr Alain Cantagrel (Toulouse), Pr Olivier Vittecoq (Rouen). We wish to thank the research nurses, the staff members of the Clinical Research Unit of Paris Centre, the staff members of the Biological Resource Center of Bichat Hospital, the staff members of the Department of Statistics of Nımes and all the investigators, and in particular Jerome Allain, Emmanuelle Dernis, Salah Ferkal, Clement Prati, Marie-Agnes Timsit, Eric Toussirot for active patient recruitment and monitoring." The biological resources centre (Paris, Bichat Hospital Claude Bernard - CRB BCB, Certificate number 34457, S. Tubiana) was in charge of centralising and managing biological data collection". 


\section{Funding}

This work was supported by the French Rheumatology Society (SFR).

\section{Availability of data and materials}

This study used data from the DESIR database locked on June 30th 2010 The datasets used and/or analysed during the current study are available from the DESIR cohort (lacohortedesir.cch@gmail.com) on reasonable request.

\section{Authors' contributions}

ARW contributed to the conception of the study, data analysis, interpretation of the results and writing of the manuscript. CL contributed to the data analysis and interpretation of the results. DN contributed to the data analysis. YD, PC and AC contributed to the interpretation of the results. ArC contributed to the study conception and interpretation of the results. All the authors take responsibility for the integrity of the work as a whole, from its inception to the published article. They specify that they had full access to all the data in the study and take responsibility for the integrity of the data and the accuracy of the data analysis. They give permission to reproduce published materials, to report sensitive personal information, to use illustrations of identifiable persons or to name persons for their contributions. All authors read and approved the final manuscript.

\section{Ethics approval and consent to participate}

The study complied with Good Clinical Practice Guidelines (clinicaltrials.gov: NCTO 164 8907, https:/clinicaltrials.gov/ct2/show/NCT01648907) and was approved by the appropriate medical ethic committee (CPP Ile-de-France III, submission number P070302).

\section{Consent for publication}

Patients gave informed consent before the start of the study including permission to publish any individual data treated anonymously.

\section{Competing interests}

The authors declare that they have no competing interests.

\section{Publisher's Note}

Springer Nature remains neutral with regard to jurisdictional claims in published maps and institutional affiliations.

\section{Author details \\ ${ }^{1}$ Centre de rhumatologie, CHU de Toulouse, UMR 1027, Inserm, Université Paul Sabatier Toulouse III, Toulouse, France. ${ }^{2}$ Centre de rhumatologie, $\mathrm{CHU}$ de Toulouse, UMR 1043, CPTP, Inserm, Université Paul Sabatier Toulouse III, Toulouse, France. ${ }^{3}$ Centre de rhumatologie, CHU de Toulouse, Toulouse, France. ${ }^{4}$ Departement de Rhumatologie, Henri Mondor Hospital, APHP, Université Paris Est Créteil, EA 7379 - EpidermE, F-94010 Créteil, France.}

Received: 4 September 2018 Accepted: 28 December 2018

\section{Published online: 15 January 2019}

\section{References}

1. Ellinghaus D, Jostins L, Spain SL, Cortes A, Bethune J, Han B, Park YR, Raychaudhuri S, Pouget JG, Hubenthal M, et al. Analysis of five chronic inflammatory diseases identifies 27 new associations and highlights diseasespecific patterns at shared loci. Nat Genet. 2016;48(5):510-8.

2. Li Z, Brown MA. Progress of genome-wide association studies of ankylosing spondylitis. Clin Transl Immunol. 2017;6(12):e163.

3. International Genetics of Ankylosing Spondylitis C, Cortes A, Hadler J, Pointon JP, Robinson PC, Karaderi T, Leo P, Cremin K, Pryce K, Harris J, et al. Identification of multiple risk variants for ankylosing spondylitis through high-density genotyping of immune-related loci. Nat Genet. 2013;45(7): 730-8.

4. Bettencourt BF, Rocha FL, Alves H, Amorim R, Caetano-Lopes J, VieiraSousa E, Pimentel-Santos F, Lima M, Porto G, Branco JC, et al. Protective effect of an ERAP1 haplotype in ankylosing spondylitis: investigating nonMHC genes in HLA-B27-positive individuals. Rheumatology (Oxford). 2013; 52(12):2168-76.

5. Evans DM, Spencer CC, Pointon JJ, Su Z, Harvey D, Kochan G, Oppermann $U$, Dilthey A, Pirinen M, Stone MA, et al. Interaction between ERAP1 and
HLA-B27 in ankylosing spondylitis implicates peptide handling in the mechanism for HLA-B27 in disease susceptibility. Nat Genet. 2011:43(8):761-7.

6. Garcia-Medel N, Sanz-Bravo A, Alvarez-Navarro C, Gomez-Molina P, Barnea E, Marcilla M, Admon A, de Castro JA. Peptide handling by HLA-B27 subtypes influences their biological behavior, association with ankylosing spondylitis and susceptibility to endoplasmic reticulum aminopeptidase 1 (ERAP1). Mol Cell Proteomics. 2014;13(12):3367-80.

7. Davidson SI, Jiang L, Cortes A, Wu X, Glazov EA, Donskoi M, Zheng Y, Danoy PA, Liu $Y$, Thomas GP, et al. Brief report: high-throughput sequencing of IL23R reveals a low-frequency, nonsynonymous single-nucleotide polymorphism that is associated with ankylosing spondylitis in a Han Chinese population. Arthritis Rheum. 2013;65(7):1747-52.

8. Reveille JD, Sims AM, Danoy P, Evans DM, Leo P, Pointon JJ, Jin R, Zhou X, Bradbury LA, Appleton LH, et al. Genome-wide association study of ankylosing spondylitis identifies non-MHC susceptibility loci. Nat Genet. 2010;42(2):123-7.

9. Dougados M, Etcheto A, Molto A, Alonso S, Bouvet S, Daures JP, Landais P, d'Agostino MA, Berenbaum F, Breban M, et al. Clinical presentation of patients suffering from recent onset chronic inflammatory back pain suggestive of spondyloarthritis: the DESIR cohort. Joint Bone Spine. 2015;82(5):345-51.

10. Rudwaleit M, Landewe R, van der Heijde D, Listing J, Brandt J, Braun J, BurgosVargas R, Collantes-Estevez E, Davis J, Dijkmans B, et al. The development of Assessment of SpondyloArthritis international Society classification criteria for axial spondyloarthritis (part I): classification of paper patients by expert opinion including uncertainty appraisal. Ann Rheum Dis. 2009;68(6):770-6.

11. Amor B, Dougados M, Mijiyawa M. Criteria of the classification of spondylarthropathies. Revue du rhumatisme et des maladies osteoarticulaires. 1990;57(2):85-9.

12. Dougados $M$, van der Linden $S$, Juhlin R, Huitfeldt B, Amor B, Calin A, Cats A, Dijkmans B, Olivieri I, Pasero G, et al. The European Spondylarthropathy Study Group preliminary criteria for the classification of spondylarthropathy. Arthritis Rheum. 1991;34(10):1218-27.

13. van der Linden S, Valkenburg HA, Cats A. Evaluation of diagnostic criteria for ankylosing spondylitis. A proposal for modification of the New York criteria. Arthritis Rheum. 1984;27(4):361-8.

14. Rudwaleit M, Jurik AG, Hermann KG, Landewe R, van der Heijde D, Baraliakos X, Marzo-Ortega H, Ostergaard M, Braun J, Sieper J. Defining active sacroiliitis on magnetic resonance imaging (MRI) for classification of axial spondyloarthritis: a consensual approach by the ASAS/OMERACT MRI group. Ann Rheum Dis. 2009;68(10):1520-7.

15. van den Berg R, Lenczner G, Thevenin F, Claudepierre P, Feydy A, Reijnierse M, Saraux A, Rahmouni A, Dougados M, van der Heijde D. Classification of axial SpA based on positive imaging (radiographs and/or MRI of the sacroiliac joints) by local rheumatologists or radiologists versus central trained readers in the DESIR cohort. Ann Rheum Dis. 2015;74(11):2016-21.

16. Maksymowych WP, Inman RD, Salonen D, Dhillon SS, Krishnananthan R, Stone M, Conner-Spady B, Palsat J, Lambert RG. Spondyloarthritis Research Consortium of Canada magnetic resonance imaging index for assessment of spinal inflammation in ankylosing spondylitis. Arthritis Rheum. 2005;53(4):502-9.

17. Hermann KG, Baraliakos X, van der Heijde DM, Jurik AG, Landewe R, MarzoOrtega H, Ostergaard M, Rudwaleit M, Sieper J, Braun J, et al. Descriptions of spinal MRI lesions and definition of a positive MRI of the spine in axial spondyloarthritis: a consensual approach by the ASAS/OMERACT MRI study group. Ann Rheum Dis. 2012;71(8):1278-88.

18. Braun J, Baraliakos X, Golder W, Brandt J, Rudwaleit M, Listing J, Bollow M, Sieper J, Van Der Heijde D. Magnetic resonance imaging examinations of the spine in patients with ankylosing spondylitis, before and after successful therapy with infliximab: evaluation of a new scoring system. Arthritis Rheum. 2003:48(4):1126-36.

19. de Hooge M, Pialat JB, Reijnierse M, van der Heijde D, Claudepierre P, Saraux A, Dougados M, Feydy A. Assessment of typical SpA lesions on MRI of the spine: do local readers and central readers agree in the DESIR-cohort at baseline? Clin Rheumatol. 2017;36(7):1551-9.

20. van den Berg R, Lenczner G, Feydy A, van der Heijde D, Reijnierse M, Saraux A, Rahmouni A, Dougados M, Claudepierre P. Agreement between clinical practice and trained central reading in reading of sacroiliac joints on plain pelvic radiographs. Results from the DESIR cohort. Arthritis Rheum. 2014; 66(9):2403-11.

21. Lin $\mathrm{JH}$, Lee WC. Testing for mechanistic interactions in long-term follow-up studies. PLoS One. 2015;10(3):e0121638.

22. Oppmann B, Lesley R, Blom B, Timans JC, Xu Y, Hunte B, Vega F, Yu N, Wang J, Singh K, et al. Novel p19 protein engages IL-12p40 to form a 
cytokine, IL-23, with biological activities similar as well as distinct from IL-12. Immunity. 2000;13(5):715-25.

23. Wang X, Lin Z, Wei Q, Jiang Y, Gu J. Expression of IL-23 and IL-17 and effect of IL-23 on IL-17 production in ankylosing spondylitis. Rheumatol Int. 2009; 29(11):1343-7.

24. Baeten D, Sieper J, Braun J, Baraliakos X, Dougados M, Emery P, Deodhar A, Porter B, Martin R, Andersson M, et al. Secukinumab, an interleukin-17A inhibitor, in ankylosing spondylitis. N Engl J Med. 2015;373(26):2534-48.

25. McInnes IB, Kavanaugh A, Gottlieb AB, Puig L, Rahman P, Ritchlin C, Brodmerkel C, Li S, Wang Y, Mendelsohn AM, et al. Efficacy and safety of ustekinumab in patients with active psoriatic arthritis: 1 year results of the phase 3, multicentre, double-blind, placebo-controlled PSUMMIT 1 trial. Lancet. 2013;382(9894):780-9.

26. Garcia-Medel N, Sanz-Bravo A, Van Nguyen D, Galocha B, Gomez-Molina P, Martin-Esteban A, Alvarez-Navarro C, de Castro JA. Functional interaction of the ankylosing spondylitis-associated endoplasmic reticulum aminopeptidase 1 polymorphism and HLA-B27 in vivo. Mol Cell Proteomics. 2012;11(11):1416-29.

27. Kadi A, Costantino F, Izac B, Leboime A, Said-Nahal R, Garchon HJ, Chiocchia G, Breban M. Brief report: the IL23R nonsynonymous polymorphism rs1 1209026 is associated with radiographic sacroilitis in spondyloarthritis. Arthritis Rheum. 2013;65(10):2655-60.

Ready to submit your research? Choose BMC and benefit from:

- fast, convenient online submission

- thorough peer review by experienced researchers in your field

- rapid publication on acceptance

- support for research data, including large and complex data types

- gold Open Access which fosters wider collaboration and increased citations

- maximum visibility for your research: over $100 \mathrm{M}$ website views per year

At $\mathrm{BMC}$, research is always in progress.

Learn more biomedcentral.com/submissions 